06.1

\title{
Равновесные параметры бислойного графена, заполненного молекулами фуллерена $\mathrm{C}_{60}$
}

\author{
() С.Ш. Рехвиашвили, М.М. Бухурова
}

Институт прикладной математики и автоматизации КБНЦ РАН, Нальчик, Россия

E-mail: rsergo@mail.ru

Поступило в Редакцию 15 декабря 2020г.

В окончательной редакции 15 декабря 2020 г.

Принято к публикации 10 января 2021г.

\begin{abstract}
Рассчитаны толщина и удельная энергия когезии сандвич-структуры в виде бислойного графена с плотноупакованными молекулами $\mathrm{C}_{60}$ внутри. Полученные значения параметров $\left(1.32 \mathrm{~nm}\right.$ и $\left.0.358 \mathrm{~J} / \mathrm{m}^{2}\right)$ согласуются с известными экспериментальными данными по гибридным углеродным наноструктурам и графиту.
\end{abstract}

Ключевые слова: бислойный графен, фуллерены, сандвич-структура, межатомные взаимодействия, равновесные параметры.

DOI: 10.21883/PJTF.2021.08.50847.18655

В экспериментальных [1-3] и теоретических [4-8] работах изучались свойства такого гибридного углеродного наноматериала, как бислойный графен с молекулами фуллерена $\mathrm{C}_{60}$ внутри. Достаточно много современных сведений о различных фуллерен-графеновых структурах представлено в обзоре [9]. Отметим, что в качестве методов получения сандвич-структур, состоящих из графеновых листов и молекул фуллерена, используются термическое испарение, интеркалирование и химические реакции. Основным инструментом теории уже традиционно является компьютерное моделирование с применением методов молекулярной динамики и функционала электронной плотности.

В настоящей работе предлагается аналитический метод расчета сандвич-структуры на основе бислойного графена и молекул фуллерена $\mathrm{C}_{60}$. Метод основан на континуальном приближении для потенциалов межатомного взаимодействия. Суть заключается в усреднении парного межатомного потенциала по поверхностям и объемам взаимодействующих компонентов. Такое усреднение представляется вполне оправданным, так как молекулы $\mathrm{C}_{60}$ в межплоскостном пространстве могут быть ориентированы случайным образом по вращательным степеням свободы (см. [1]). Данный метод использовался нами в $[10,11]$ для расчета систем, содержащих углеродные нанотрубки, фуллерены и нанолуковицы.

Будем рассматривать плотноупакованный монослой молекул фуллерена $\mathrm{C}_{60}$, который находится между двумя идеальными листами графена. Слоевая концентрация молекул равна $2 /\left(\sqrt{3} a^{2}\right)$, где $a=1.01 \mathrm{~nm}$ - расстояние между центрами соседних молекул. Предполагается, что в системе отсутствуют какие-либо деформации. В качестве парного потенциала воспользуемся формулой Леннарда-Джонса, которую запишем в виде

$$
\phi(r)=D\left[\left(\frac{r_{0}}{r}\right)^{12}-2\left(\frac{r_{0}}{r}\right)^{6}\right]
$$

где $D=3.202 \mathrm{eV}$ и $r_{0}=0.3985 \mathrm{~nm}$ - глубина потенциальной ямы и равновесное расстояние для двух атомов углерода. Численные значения параметров потенциала взяты из работы [12], в которой методом молекулярной динамики изучались свойства смеси молекул фуллерена с монооксидом углерода. Удельная энергия графен-графен есть

$$
W_{1}(z)=2 \pi n_{s}^{2} \int_{z}^{\infty} \phi(r) r d r
$$

где $z$ - расстояние между двумя плоскостями графена, $n_{s}=3.82 \cdot 10^{19} \mathrm{~m}^{-2}$-поверхностная плотность атомов графена. После подстановки (1) в (2) и интегрирования получаем

$$
W_{1}(z)=\pi n_{s}^{2} D r_{0}^{2}\left[\frac{1}{5}\left(\frac{r_{0}}{z}\right)^{10}-\left(\frac{r_{0}}{z}\right)^{4}\right] .
$$

Из условия равновесия $d W_{1}(z) / d z=0$ при $z=z_{0}$ находим основные параметры бислойного графена- равновесное межплоскостное расстояние и удельную энергию когезии:

$$
z_{0}=\frac{r_{0}}{\sqrt[6]{2}}, \quad W_{G}=-W_{1}\left(z_{0}\right)=\frac{6 \pi D\left(n_{s} z_{0}\right)^{2}}{5} .
$$

Учитывая численные значения параметров парного потенциала, получаем $z_{0}=0.355 \mathrm{~nm}$ и $W_{G}=0.356 \mathrm{~J} / \mathrm{m}^{2}$. Значение параметра $z_{0}$ почти совпадает с межплоскостным расстоянием в графите $0.35 \mathrm{~nm}$; удельная энергия когезии хорошо согласуется с экспериментальным значением удельной энергии скола графита $0.37 \pm 0.01 \mathrm{~J} / \mathrm{m}^{2}[13]$. Данные оценки позволяют сделать заключение о надежности выбранных численных значений параметров потенциала (1).

Чтобы найти удельную энергию взаимодействия слоя молекул $\mathrm{C}_{60}$ с графеном, требуется усреднить парный 
потенциал по сферической поверхности молекулы и бесконечной плоскости. Это приводит к общему выражению вида

$$
W_{2}(z)=\frac{120 \pi n_{s}}{\sqrt{3} a^{2}} \int_{z}^{\infty}\left\{\int_{-1}^{1} \phi\left(\sqrt{r^{2}+R^{2}+2 r R x}\right) d x\right\} r d r
$$

где $z$ - расстояние от центра молекул фуллерена до плоскости графена, $R=0.355 \mathrm{~nm}$ - радиус молекулы фуллерена $\mathrm{C}_{60}$. Вычисление (5) с учетом (1) дает

$$
\begin{aligned}
W_{2}(z) & =\frac{4 \sqrt{3} \pi n_{s} r_{0}^{3} D}{9 R a^{2}}\left\{\left(\frac{r_{0}}{z-R}\right)^{9}-\left(\frac{r_{0}}{z+R}\right)^{9}\right. \\
& \left.-15\left[\left(\frac{r_{0}}{z-R}\right)^{3}-\left(\frac{r_{0}}{z+R}\right)^{3}\right]\right\} .
\end{aligned}
$$

Формулы (3) и (6) позволяют определить равновесную конфигурацию рассматриваемой сандвич-структуры.

В аддитивном приближении полная удельная энергия системы равна

$$
W(z)=W_{1}(2 z)+2 W_{2}(z) .
$$

Условие равновесия $d W(z) / d z=0$ при $z=z_{0}$ с учетом (3), (6) и (7) сводится к нелинейному уравнению

$$
\begin{gathered}
F\left(5,2, \frac{r_{0}}{2 z_{0}}\right)+C\left[F\left(4,5, \frac{r_{0}}{z_{0}-R}\right)\right. \\
\left.-F\left(4,5, \frac{r_{0}}{z_{0}+R}\right)\right]=0, \\
F(n, m, y)=y^{n}\left(m-y^{6}\right), \\
C=\frac{2 \sqrt{3} r_{0}}{R a^{2} n_{s}}=0.1 .
\end{gathered}
$$

Уравнение (8) решалось итерационным методом секущих с точностью до трех знаков после запятой. Вычисленные равновесные параметры наноструктуры: толщина $d=2 z_{0}=1.32 \mathrm{~nm}$; удельная энергия когезии $W_{G F}=-W\left(z_{0}\right)=0.358 \mathrm{~J} / \mathrm{m}^{2}$. Под когезией в данном случае нами понимается взаимное сцепление составных частей наноструктуры - двух листов графена и слоя молекул $\mathrm{C}_{60}$. Значение $d$ согласуется с экспериментальными данными из работы [3], по которым толщина бислойного оксида графена, заполненного молекулами фуллерена, находится в интервале 0.91-1.56 nm. Как и в случае простого бислойного графена, удельная энергия когезии здесь оказывается близкой по своему значению к удельной энергии скола графита.

Таким образом, на основании данных настоящей работы приходим к нетривиальным выводам: 1) несмотря на существенное различие в толщине (почти в 4 раза), удельная энергия когезии бислойного графена с плотноупакованным слоем молекул фуллерена $\mathrm{C}_{60}$ внутри практически равна удельной энергии когезии простого бислойного графена $\left.\left(W_{G F} \approx W_{G}\right) ; 2\right)$ радиус молекулы фуллерена $\mathrm{C}_{60}$ и межплоскостные расстояния в графите и простом бислойном графене с высокой точностью совпадают друг с другом.

\section{Конфликт интересов}

Авторы заявляют, что у них нет конфликта интересов.

\section{Список литературы}

[1] M. Ishikawa, S. Kamiya, S. Yoshimoto, M. Suzuki, D. Kuwahara, N. Sasaki, K. Miura, J. Nanomater., 2010, 891514 (2010). DOI: 10.1155/2010/891514

[2] R. Mirzayev, K. Mustonen, M.R.A. Monazam, A. Mittelberger, T.J. Pennycook, C. Mangler, T. Susi, J. Kotakoski, J.C. Meyer, Sci. Adv., 3 (6), e1700176 (2017). DOI: $10.1126 /$ sciadv.1700176

[3] X. Tang, Y. Qu, Sh. Deng, Y. Tan, Q. Zhang, Q. Liu, J. Mater. Chem. A, 6 (45), 22590 (2018). DOI: 10.1039/C8TA08261H

[4] M. Kirca, Composites B, 79, 513 (2015). DOI: $10.1016 /$ j.compositesb.2015.04.050

[5] Z. Ozturk, C. Baykasoglu, M. Kirca, Int. J. Hydrogen Energy, 41 (15), 6403 (2016). DOI: 10.1016/j.ijhydene.2016.03.042

[6] J.M. Devi, Bull. Mater. Sci., 42 (2), 75 (2019). DOI: $10.1007 / \mathrm{s} 12034-019-1753-0$

[7] D. Mao, X. Wang, G. Zhou, L. Chen, J. Chen, S. Zeng, J. Mol. Model., 26 (7), 166 (2020). DOI: $10.1007 / \mathrm{s} 00894-020-04417-1$

[8] А.А. Артюх, Л.А. Чернозатонский, Письма в ЖЭТФ, 111 (2), 93 (2020). DOI: 10.1134/S0021364020020058

[9] M. Chen, R. Guan, Sh. Yang, Adv. Sci., 6 (1), 1800941 (2019). DOI: 10.1002/advs.201800941

[10] С.Ш. Рехвиашвили, М.М. Бухурова, Письма в ЖТФ, 44 (23), 24 (2018). DOI: 10.1134/S1063785018120349

[11] С.Ш. Рехвиашвили, М.М. Бухурова, Письма в ЖТФ, 45 (12), 9 (2019). DOI: 10.1134/S1063785019060294

[12] S. Pałucha, Z. Gburski, J. Biesiada, J. Mol. Struct., 704 (1-3), 269 (2004). DOI: 10.1016/j.molstruc.2004.02.044

[13] W. Wang, S. Dai, X. Li, J. Yang, D.J. Srolovitz, Q. Zheng, Nature Commun., 6, 7853 (2015).

DOI: $10.1038 /$ ncomms 8853 